\title{
Study on the promotion impact of demand response on distributed PV penetration by using non- cooperative game theoretical analysis
}

\section{AUTHOR(S):}

Wang, Ge; Zhang, Qi; Li, Hailong; McLellan, Benjamin C.; Chen, Siyuan; Li, Yan; Tian, Yulu

\section{CITATION:}

Wang, Ge ...[et al]. Study on the promotion impact of demand response on distributed PV penetration by using non-cooperative game theoretical analysis. Applied Energy 2017, 185(2): 1869-1878

\section{ISSUE DATE:}

2017-01-01

\section{URL:}

http://hdl.handle.net/2433/246271

\section{RIGHT:}

(C) 2017. This manuscript version is made available under the CC-BY-NC-ND 4.0 license http://creativecommons.org/licenses/by-nc-nd/4.0/.; この論文は出版社版でありません 。引用の際には出版社版をご確認ご利用ください。; This is not the published version. Please cite only the published version. 


\section{Study on the Promotion Impact of RTP-based Demand} Response on Distributed PV Penetration by using a NonCooperative Game Theoretical Analysis

\section{GE WANG}

Academy of Chinese Energy Strategy,

China University of Petroleum at Beijing

QI ZHANG (CORRESPONDING AUTHOR)

Academy of Chinese Energy Strategy,

China University of Petroleum-Beijing, Changping, Beijing 102249, China

Email: zhangqi@cup.edu.cn; zhangqi56@tsinghua.org.cn

Benjamin C. McLellan

Graduate School of Energy Science

Kyoto University, Japan

\section{HAILONG LI}

School of Business, Society and Engineering,

Mälardalen University, Sweden

\section{Yan LI}

Academy of Chinese Energy Strategy,

China University of Petroleum at Beijing

\section{SIYUAN CHEN}

Academy of Chinese Energy Strategy,

China University of Petroleum at Beijing 


\section{Abstract}

Promoting the penetration of distributed photovolataic systems (PV) at the enduser side is an important contribution to carbon reduction. This study aims to evaluate the promotion impact of the level of smart consumers on the installation of distributed PV using a non-cooperative game theoretical model, which can find the Nash equilibrium of residential smart consumers with different levels of demand control capability in a electricity power market with real-time pricing mechanism under different installed PV capacities and battery capacities. As a case study, 5 levels of smart control, 32 combinations of PV installed capacities and battery capacities were analyzed and inter-compared using the developed model. The results show that: (i) the consumers with higher smart control level are able to accept larger PV capacity because the marginal revenue of new installed PV for smart consumers decreases much more slowly compared to that of a common consumer; (ii) the smarter consumers need less batteries to promote PV economic acceptability; (iii) the smarter consumers can meet the electricity demand in real-time with least expenditure thanks to their advanced demand-response capability, so they get more ultimate benefit from the games. 


\section{$52 \quad$ Nomenclature}

\section{Indices}

$54 \mathrm{t} \quad$ hour series in a day (1-24)

55 d representative days (3 typical days)

$56 \quad \mathrm{i}, \mathrm{j} \quad$ user group (1-5)

57 c controllable appliances

58

59 Parameters

60 NCL(i,d,t) non-controllable load (kW)

61 STA(i,d,c) earliest start time of one controllable appliance

62 STO(i,d,c) latest stop time of one controllable appliance

$63 \mathrm{RP}(\mathrm{i}, \mathrm{d}, \mathrm{c}) \quad$ rated power of one controllable appliance $(\mathrm{kWh})$

$64 \operatorname{IRR}(\mathrm{d}, \mathrm{t}) \quad$ solar irradiation in terms of output power/rated power (\%)

65 DAYS(d) amount of days represented by representative day in each year

66 PV(i) installed PV capacity $(\mathrm{kWh})$

67 BA(i) installed battery capacity (kWh)

$68 \alpha, \beta \quad$ coefficient of electricity price

$69 \quad \mathrm{NRL}(\mathrm{d}, \mathrm{t}) \quad$ non-residential load $(\mathrm{kWh})$

70 CHAEFF battery charge efficiency

71 DISEFF battery discharge efficiency 


\section{$74 \quad$ Variables}

75 be(i,d,t) power bought from grid $(\mathrm{kWh})$

76 se(i,d,t) power sold to grid $(\mathrm{kWh})$

$77 \quad \mathrm{ca}(\mathrm{i}, \mathrm{d}, \mathrm{c}, \mathrm{t}) \quad$ power consumed by one controllable appliance (kWh)

$78 \operatorname{pr}(\mathrm{d}, \mathrm{t}) \quad$ power price established by power retail (RMB per $\mathrm{kWh}$ )

79 brin(i,d,t) battery charge rate (\%)

80 brout(i,d,t) battery discharge rate (\%)

81

82 Abbreviations

83 PV photovoltaic

84 FIT feed-in tariff

85 RTP real-time pricing

86 TOU time of use

87 GAMS General Algebraic Modeling System

88 MCP mixed complementarity problem

89 


\section{1. Introduction}

With the dramatic increase of fossil fuel consumption, the reduction of $\mathrm{CO}_{2}$ emission and the promotion of renewable energy have become urgent tasks for societies. $\mathrm{PV}$, as one of the most important renewable energy technologies, has been commonly used in a distributed configuration, installed very near or at the end user`s location. To promote the application of PV, many kinds of subsidization policies have been proposed [1-3]. For example, in many countries, governments provide a lump-sum grant to consumers who install PV systems or subsidies on the electricity generated by PV. Moreover, utility companies are often obligated to purchase PV power at a price relatively higher than the regular tariff under government-supported feed-in tariffs (FIT). However, in the traditional power grid, PV power is difficult to integrate due to its intermittence and low voltage [4]. Thanks to the recent rapid development of communication and automation technologies using telemetry, remote and automated control have enabled smart grid and demand response, which is expected to help dispatch and utilize PV power in both macro-grids [5, 6] and micro-grids [7, 8]. restructuring of the electricity market can also create an incentive to incorporate more PV panels [9]. Practically, energy demand is not constant, but varies from moment to moment depending on end-users patterns of usage. In order to meet the energy demand 
110 to satisfy the peak power demand rather than the average power demand, leading to an

111 over-capacity system for much of the time. In the traditional power market, the

112 electricity price is usually fixed. A fixed price cannot reflect the fluctuation of

113 generation cost caused by peak load, unit commitment constraints, congested

114 transmission lines etc., and thus consumers have no motivation to shift consumption

115 during the peak load periods. This results in a redundancy of power generation capacity

116 and transmission infrastructures in the off-peak times, and therefore, the whole system

117 becomes inefficient and cost-ineffective. To solve this problem, economic dispatch

118 based on a real-time pricing (RTP) system and demand-response technologies is

119 proposed, which can motivate consumers to shift their loads from peak times. Various

120 pricing strategies have been proposed to incentivize demand-response in smart grid,

121 and the most efficient one is the RTP $[10,11]$. Demand response programs under real-

122 time pricing markets have been widely adopted in practice, and the promotion impacts

123 on market access to distributed energy have been determined in previous studies [12].

124 There have been several models developed with a focus on the relationship

125 between demand-response and the installation capacity of distributed PV. The existing

126 models can mainly be divided into two types in terms of the mathematical methodology.

127 One type is the optimal model, including static optimization models solving optimal

128 load commitment problems of electric appliances in smart homes with distributed PV

129 installed [13-15], and dynamic optimization models solving optimal expansion

130 planning problems for PV in smart homes [16, 17]. In these optimal models, the power 
131 price is usually set as exogenous. The consumers are price-takers rather than players in

132 the market, which means that the consumers' behavior has no impact on the electricity

133 price. The other type of model is the game theoretical model, for example the non-

134 cooperative game models handling games among residential consumers equipped with

135 distributed electricity generators [18-20], Stackelberg game models dealing with games

136 between utility companies and smart end-users (such as residential smart homes) in

137 demand response programs [21], and market equilibrium models focusing on the whole

138 power market [22]. In these game theoretical models, consumers's strategies can affect

139 the power price. Compared with optimal models, game theoretical models have

140 advantages in handling situations where market participants have different or even

141 conflicting objectives, which is more realistic. However, in existing studies, the

142 differences in the smart levels of consumers, especially the difference between smart

143 consumers and non-smart consumers were not yet considered. In addition, the PV

144 installed capacities are usually exogenously given or obtained as optimal results, which

145 do not indicate the detailed impacts of the level of smart control on PV installation

146 capacities.

147 The purpose of this study is to uncover the impact of the level of smart control on

148 distributed PV installation. In order to analyze the impacts of end users' participation

149 and different smart levels of consumers in an electricity power market, a non-

150 cooperative game theoretical model was developed. In the model, consumers

151 participate in the game in a real-time pricing market and every consumer pursues his/her 
152 own minimized expenditure on electricity consumption. Different from existing studies,

153 different levels of smart control (smart levels) have been considered in the proposed

154 model to analyze their impact on the integration of distributed PV. The smart level is

155 measured by the ability to respond to price fluctuation. The development of smart

156 technologies is the foundation of the actualization of consumers' demand-response.

157 Such technologies include smart metering, remote control, and automated control, and

158 so on $[10,23]$. Newly built houses are considered to be equipped with the latest

159 commercially-effective advanced smart electric devices and consumers can therefore

160 respond to the price fluctuations quickly and flexibly. One the other hand, old houses

161 are typically not smart enough and thus cannot allocate energy consumption according

162 to price fluctuations. Consumers with different smart levels were then analyzed and

163 compared. The equilibrium results with different installed capacities of PV as well as

164 batteries were obtained. Every consumer's optimal operation pattern and total expense

165 can be clarified. The economical acceptability of PV was then evaluated, and the

166 feasibility of the methodology was demonstrated practically through its application to 167 a case study in China.

\section{2. Methodology}

\section{2.1. Model Framework}

The model framework is shown in Figure 1. Non-residential consumers, such as commercial and industrial consumers, usually have contracts with power retailers and 
172 they are charged a rate based on the time of use (TOU) of their energy. Their electricity

173 price is pre-given, and thus their consumption can be regarded as constant in the real-

174 time pricing market. On the other hand, residential consumers are bidirectionally

175 connected to the retailer. The power retailers gather consumption data and set the real-

176 time price based on the total wholesale hourly power consumption. The residential

177 consumers respond to the hourly price by shifting their power load in the form of

178 submitting new demand bids and the retailer sets a new price again. This procedure will

179 be repeated until equilibrium is achieved.

180 2.2. Residential micro-grid module

181 Residential micro-grids consist of controllable and non-controllable electric

182 appliances, distributed photovoltaic panels, batteries, and central control appliances.

183 Controllable appliances refer to appliances which can be operated at any time of the

184 day or within a particular time interval while non-controllable appliances refer to those

185 whose operation time is fixed. For example, a washing machine is controllable,

186 however, an air-conditioner is usually non-controllable. Distributed photovoltaic panels

187 are connected to the power grid, and surplus generated power can be sold to the grid at

188 the price of the feed-in tariff.

189 Using automated central control technology, residential consumers can gain real-

190 time access to market prices and the operation of controllable electric appliances can

191 be arranged automatically to avoid purchasing power during high price periods. It is

192 important to note that this type of system requires expensive technologies that may not 
193 be available to all consumers. Alternative solutions such as online real-time power price

194 access and remote control of smart appliances can substitute to some extent. Due to the 195 potential disparities in control technologies and capabilities, it is reasonable to divide 196 the residential consumers into several types according to their ability to response to 197 price fluctuation, in other words their smart level. In this paper, the smart level is 198 measured by length of the time interval in which energy consumption can be shifted. meet.

$B A(i) \times C H A E F F \times \operatorname{brin}(i, d, t)-B A(i) \times D I S E F F \times$

$\operatorname{brout}(i, d, t), \quad\left(\lambda_{\text {balance }}(i, d, t)\right) \quad \forall i, d, t$ power of PV panels at day $d$ time slot $t$; $P V(i)$ is the installed capacity of PV panels in consumer $i$ 's home; be(i,d,t) and se(i,d,t) are the volume of electricity consumer $i$ buys

210 from and sells to the grid at day $d$ time slot $t$, respectively; $c a(i, d, c, t)$ is the power 211 consumption of consumer i's specific controllable appliance $c$ at day $d$ time slot $t$.

$212 N C L(i, d, t)$ is the total power consumption of consumer i's non-controllable appliances 213 at day $d$ time slot $t$; $B A(i)$ is the installed capacity of battery in consumer i's home; 
$214 \operatorname{brin}(i, d, t)$ and $\operatorname{brout}(i, d, t)$ are the charge and discharge rate of consumer $i$ 's battery at 215 day $d$ time slot $t$. CHAEFF and DISEFF are the charge and discharge efficiency. $216 \lambda_{\text {balance }}$ is the dual variable for balance constraints.

218 these constraints for the batteries are described in equation (2-2) - (2-6), respectively. 219 Particularly, equation (2-6) means the batteries should not be charged and discharged 220 simultaneously, which is a logical constraint.

$2240 \leq \operatorname{brin}(i, d, t) \leq 1, \forall i, d, t$

$2250 \leq \operatorname{brout}(i, d, t) \leq 1, \forall i, d, t$

$226 \operatorname{brin}(i, d, t) \times \operatorname{brout}(i, d, t)=0,\left(\lambda_{B A-\text { logical }}(i, d, t)\right), \forall i, d, t$

$234 c a(i, d, c, t) \equiv 0, \forall t<S T A(i, d, c) \quad$ or $\quad t>S T O(i, d, c)$ 
244 eliminated, which is shown in equation (2-10). On the other hand, logically, the consumers should not purchase electricity power from and sell electricity power to the

246 retailer simultaneously. This is shown in equation (2-11).

$\operatorname{se}(i, d, t) \times b e(i, d, t)=0,\left(\lambda_{\text {CONSUMER-logical }}(i, d, t)\right), \forall i, d$

\subsection{Retailer pricing module}

The obligation of the retailer is to meet electricity demand from all consumers.

253 Retailers purchase electricity from a variety of sources in a wholesale electricity market,

254 in which the electricity is generated by a variety of technologies and fuels. Each 255 technology has a different marginal cost, which is defined as the incremental cost 
256 incurred to produce an additional unit of electric power. Naturally, (unless otherwise

257 compelled) the retailer will purchase electricity from the cheapest source first, leading

258 ultimately to a non-decreasing marginal cost curve. Therefore, if the retailer wants to

259 earn a fixed ratio profit, it is reasonable to approximately assume that the supply-price

260 curve is non-decreasing.

261 In this paper, an average-cost based pricing scheme is used as shown by equation

262 (2-12). Here, the $N R L(d, t)$ is the non-residential electricity power load at day $d$ time slot

$263 t$, which is set to be an exogenous constant, and the $\alpha$ and $\beta$ are coefficients.

264

265

$p r(d, t)=\alpha \frac{\sum_{i}[b e(i, d, t)-s e(i, d, t)]+N R L(d, t)}{\frac{\left[\sum_{t} \sum_{i} N C L(i, d, t)+\sum_{i} \Sigma_{c} R P(i, d, c)-\sum_{t} \sum_{i} P V(i) \times I R R(d, t)+N R L(d, t)\right]}{24}}+$

$266 \beta,\left(\lambda_{\text {price }}(d, t)\right), \forall d, t$

267 Such a pricing function can ensure the supply-price curve is non-decreasing.

268 Furthermore, the pricing mechanism also encourages users to schedule their energy

269 consumption and batteries in a way that the energy demand is more equally distributed

270 over all time slots. As shown in the equation, $\alpha+\beta$ is the average price.

\section{2.4. Non-cooperation game theoretical complementarity model}

The objective of each residential consumer is to minimize his/her energy

273 expenditure on electricity consumption in a whole year as is shown in formula (2-13).

274 Each consumer decides his/her own load commitment and battery operation pattern. All

275 information is public and there is no collusion between consumers. Therefore this is a

276 typical non-cooperation game. 
$\min _{b e, s e, b c, p v}\left\{\sum_{d}\left[\sum_{t} \operatorname{pr}(d, t) \times b e(i, d, t)-\sum_{t} F I T \times P V(i) \times I R R(d, t)\right] \times\right.$ conditions are necessary and sufficient for the optimization of the objective function.

Since the non-cooperation game model is a simultaneous-move game, solving the KKT

$$
\lambda_{\text {CONSUMER-logical }}(i, d, t) \times \operatorname{se}(i, d, t) \perp b e(i, d, t), \forall i, d, t
$$


298

299

$(2-16)$

300

301

302

303

304

305

306

307

308

309

310

$-\lambda_{\text {balance }}(i, d, t)+\lambda_{C A-\text { power }}(i, d, c) \perp c a(i, d, c, t), \forall i, d, c, t$

$-\lambda_{\text {balance }} \times B A(i) \times C H A E F F+\sum_{k=0}^{t} \lambda_{B A-u p p e r}(i, d, t)-$

$\sum_{k=0}^{t} \lambda_{B A-\text { lower }}(i, d, t)+\lambda_{B A-\text { logical }}(i, d, t) \times \operatorname{brout}(i, d, t) \perp \operatorname{brin}(i, d, t), \forall i, d, t$

$-\lambda_{\text {balance }} \times B A(i) \times C H A E F F-\sum_{k=0}^{t} \lambda_{B A-u p p e r}(i, d, t)+$

$\sum_{k=0}^{t} \lambda_{B A-\text { lower }}(i, d, t)+\lambda_{B A-\text { logical }}(i, d, t) \times \operatorname{brin}(i, d, t) \perp \operatorname{brout}(i, d, t), \forall i, d, t$

$\sum_{i} b e(i, d, t) \times D A Y S(d)+\lambda_{\text {price }}(d, t) \perp \operatorname{pr}(d, t), \forall d, t$

\subsection{Tool}

The non-cooperation game theoretical complementarity model is developed in the

General Algebraic Modeling System (GAMS) [25] as a mixed complementarity

problem (MCP). The mathematical properties of existence and uniqueness for the MCP

solution can be found in [26, 27]. In the present study, the MCP problem is solved using the PATH solver [28]. It takes 68s to solve this problem on a computer with i7 $2.5 \mathrm{GHZ}$

CPU and 4G memory. 
319 complex and large-scale linear, nonlinear, integer, and complementarity problems. The

320 PATH solver is a Newton-based algorithm for solving complementarity problems.

\section{$321 \quad$ 3. Case study}

The developed non-cooperation game theoretical power market complementarity model was applied to a district in China. All the residential consumers participate in the real-time pricing program. To investigate the promotion impact of smart levels of residential consumers on the acceptability of distributed PV power, the economic performance of installed PV power, consumers' expenditure on power consumption and the optimal operation pattern of electric appliances under the non-cooperation game will be analyzed using the proposed model.

\subsection{Data}

331 Residential consumers always arrange their electric appliances’ operations according

332 to their life style arbitrarily when demand response is not involved. Seasonal difference

333 is also a factor in determining the load pattern. In summer and winter, the load is 334 relatively higher than that in spring and autumn due to the high electricity demand for cooling and heating. Therefore, three representative days for summer, winter, and mid- 


\subsubsection{Non-residential load}

Non-residential load data was obtained using a foreign city as reference [6] $]$. In China, non-residential load accounts for $80 \%$ of the total load [29]. The non-residential consumers don't respond to real-time price as described in Section 2, therefore their

341 load is constant, as is shown in Figure 2. The peak load appears at noon and the lowest

342 load appears before dawn. The power load in summer and winter is higher than that in 343 a typical mid-seasonal day.

\subsubsection{Residential load and variable time zone}

Taking reference [30] as reference basis, we conducted a survey on the residential consumers' life style with regards to electricity consumption. Eleven households were sampled, and their electric appliances' daily operation patterns were recorded. all the non-controllable appliances as shown in Figure 3. The second part is the controllable load, which consists of all the controllable appliances, and the initial distribution of the controllable load is depicted in Figure 4.

354 to different demand response abilities (smart levels) in houses constructed in different 355 technical eras. In the present study, five types of residential consumers with different 356 abilities to respond to price changes have been taken into consideration. The smart 
357 house technologies available to them in order of their houses' age are: (1) automated

358 controller and access to real-time price data; (2) remote controller and access to real-

359 time price data; (3) timing start and access to real-time price data; (4) only access to

360 real-time price; and (5) no access to even real-time price, in reverse order of increased

361 smart level respectively. To quantify their different smart levels, it is assumed that the

362 length of the time interval during which energy consumption can be shifted is 24 hours

363 for consumer 1, 11 hours for the consumer 2, 5 hours for the consumer 3, 3 hours for

364 the consumer 4, and 1 hour for the consumer 5 , respectively.

365 In the present study, we take consumer 3 as an example to illustrate the meaning

366 of the time interval length: if resident 3 is accustomed to using the washing machine at

367 1:00 pm before going out to work in the afternoon, he can choose to shift the operation

368 within the time interval $11: 00$ am to $3: 00 \mathrm{pm}$, of which 1:00 pm is the midpoint. In

369 particular, consumer 1 can shift his load to any other hour within the day and consumer

3705 cannot shift any load.

371 Each type of residential consumer includes 1000 households. The 5000 households

372 share the same non-controllable load and initial controllable load.

\section{3.1.3. Solar irradiation}

374 The solar irradiation corresponding to the three representative days is depicted in

375 Figure 5. The amount of PV generation power can be calculated by equation (3-1). [6, 
379

where, $\eta_{P V}$ is the conversion efficiency of the solar cell array (14.4\%), PV is the

rated capacity of PV panels, $I_{P V I}$ is the solar irradiation on an inclined surface $\left(\mathrm{kW} / \mathrm{m}^{2}\right)$,

$I R R=P_{P V} /_{P V}=\eta_{P V} \times I_{P V I} \times\left(1-0.005 \times\left(t_{C R}-25\right)\right)$

\subsection{Policy assumptions}

In this paper, the subsidy policy for distributed PV panels is assumed to be a fixed

\subsection{Simulation study}


398 benefit results. The numerical results will be provided in Section 4.

399

400

401 the lowest smart level consumer. This indicates that the batteries can reduce the 414 economic performance gap between consumers with different smart levels. The reasons

\subsection{Electricity expense}

The simulations were run for all the combinations of PV capacities and battery capacities. The annual total expenditures of each type of consumers on electricity power consumption have been summarized in Figure 6 in the form of the annual expenses saved comparing to consumer 5 , whose smart level is the lowest. The saved money is the value of the "smart level". As shown in the results, consumers with higher smart levels can save more money. With the PV installed capacity increase, the superiorities become even more significant. When there is a $3.5 \mathrm{~kW}$ PV but no battery, a consumer with the highest smart level will spend 36.6\% less expenditure than the consumer with the lowest smart level annually. However, when same capacity battery is integrated, the superiorities in saving electricity expenditure of the consumers with higher smart level are attenuated compared to low smart level ones. For example, with 2 kWh battery and $3.5 \mathrm{~kW}$ PV, a consumer with the highest smart level can save only $25.2 \%$ compared to

\section{Result}




\subsection{Marginal revenue of $P V$ power}

The cost of PV panels and batteries have not been counted into the expenses in this study, because we only focus on the promotion impacts of the consumers' smart levels on the integration of PV power. Moreover, the cost of PV panels and battery modules are reducing dramatically year by year $[33,34]$. Therefore, the marginal revenue was considered a more reasonable index than levelised cost of electricity. Marginal revenue is the increment when capacity increases one unit. In practice, if the capital cost of a certain capacity of PV is less than its marginal revenue, it is economically acceptable. consumers with lower smart levels (consumer 4 and consumer 5) have sharply dropping marginal revenue. For consumer 5, the marginal revenue of each $0.5 \mathrm{~kW}$ PV panel decreased from 404 RMB for the first unit PV panel, to 85 RMB for the seventh PV panel. However, for consumer 1, the marginal revenue of each $0.5 \mathrm{~kW}$ PV panel only decreased from 399 RMB for the first unit PV panel, to 341 RMB for the seventh unit PV panel. The difference indicates that the higher the smart level of the consumers, the more PV panels can be economically acceptable. Furthermore, batteries can help the

434 consumers with lower smart levels to delay the decrease of PV marginal revenue 435 effectively. Taking consumer 3 as an example, the marginal revenue of PV starts to 436 decrease sharply when PV capacity is $1.5 \mathrm{~kW}$ when there is no battery; and the turning 
point of marginal revenue of PV moves to $2 \mathrm{~kW}$ PV capacity when there is a $1 \mathrm{kWh}$

438

439

battery. Furthermore, the turning point will move to $2.5 \mathrm{~kW}$ and $3 \mathrm{~kW}$ PV capacity respectively when $2 \mathrm{kWh}$ and $3 \mathrm{kWh}$ batteries are deployed.

On the other hand, according to the numerical result shown in Figure 7, compared to consumers 3, 4 and 5, the battery has no obvious impacts on the marginal revenue of PV for consumer 1 and consumer 2 whose smart level is relatively higher. Therefore, consumers with a high smart level can economically accept a large generating capacity of PV power, and thus the battery contributes little in further promoting distributed PV installation for them.

\subsection{Price variance under different situations}

The daily price variance can be calculated by equation (4-1).

price varianve $=\frac{1}{24-1} \sum_{t}\left(\operatorname{pr}(d, t)-\frac{1}{24} \sum_{t} \operatorname{pr}(d, t)\right)^{2}$

The price variances under different situations are exhibited in Figure 8. It is depicted that the price variance decreases with the increase of battery capacity. The consumers with high smart levels are able to utilize the price fluctuation to save money by purchasing electricity power during lower price periods. Since the total load is the same for all the consumers, the different smart levels do not cause any difference when the price variances become zero (price is a constant). In other words, smarter consumers can benefit from higher price variance more. 
batteries can help consumers with relatively lower smart levels to promote PV panel costs of these alternative installations should also be carefully considered with regards to appropriate subsidisation and investment.

\subsection{Operation pattern}

When the non-cooperative game reaches an equilibrium state, every consumer's appliance operation pattern is considered to be optimal. The equilibrium was obtained

473 from the hour-by-hour simulation and the feasibility was inherent. A typical day in

474 summer with $1 \mathrm{kWh}$ battery, 3kW PV was chosen as an example. The operation patterns

475 of consumer 1 and consumer 5 are shown in Figure 9. It is apparent that consumer 1

476 responds to the real-time price by using more power when the price is lower before 477 dawn and using less power when price is higher in the evening. 


\section{Conclusion}

In the present study, a non-cooperation game theoretical power market complementarity model was developed to study the equilibrium real-time power price for residential consumers considering smart residential micro-grid and distributed PV panels. The model was applied to case studies to uncover the impacts of smart levels 483 on the economic integration of distributed PV power, and the impacts of PV capacities and battery capacities on consumers’ power expenses.

Five types of residential consumers with different capabilities of responding to 486 price changes were considered to be playing in the game and 32 different combinations of battery capacities and PV capacities were simulated. The results show that: (a) residential consumers with higher smart levels at higher integration of PV are able to benefit more from the non-cooperative game in form of saving money on electricity expenditure. The preponderances increase with the increase in PV capacity and 491 decrease with the increase of battery capacity. In this study, consumers with the highest 492 smart level can save $36.6 \%$ on electricity expenditure compared to the consumers with 493 the lowest smart level at most; (b) the marginal revenue of new installed PV panels 494 decreases for all residential consumers. However, consumers with lower smart level 495 suffer a sharper drop. The difference of the marginal revenue among different users can 496 reach 300\% in this study. It can be concluded that consumers with higher smart levels 497 are able to economically integrate a larger PV capacity. (c) Batteries can help consumers 
498 with relatively low smart levels to mitigate the decrease of PV marginal revenue, 499 however, they cannot significantly raise the PV marginal revenue for consumers with 500 high smart levels.

501 The real-time power price was obtained simultaneously. By analyzing the price, it 502 is uncovered that consumers with lower smart levels get more benefit from the increase 503 of battery capacity as a result of the decrease of price variances. When there is no PV, 504 the price variance in a typical summer day as an example decreases by $94.4 \%$ with the 505 integrated battery capacity increasing from 0 to $3 \mathrm{kWh}$ and the electricity consumption 506 difference between consumers with highest and lowest smart level decreases by 50\%. 507 


\section{$508 \quad$ Figures}

$509 \quad$ Figure 1 Structure of the target system

$510 \quad$ Figure 2 Non-residential electricity load

$511 \quad$ Figure 3 Non-controllable load of one household

$512 \quad$ Figure 4 Initial controllable load of one household

$513 \quad$ Figure 5 Solar irradiation coefficient in different seasons

514 Figure 6 Saved annual electricity power expense of one household comparing to consumer 5 under different PV and battery capacity

$516 \quad$ Figure 7 Marginal revenue of new installed PV capacity under different battery capacity

518 Figure 8 Daily variance of real-time power price under different PV and battery capacity 


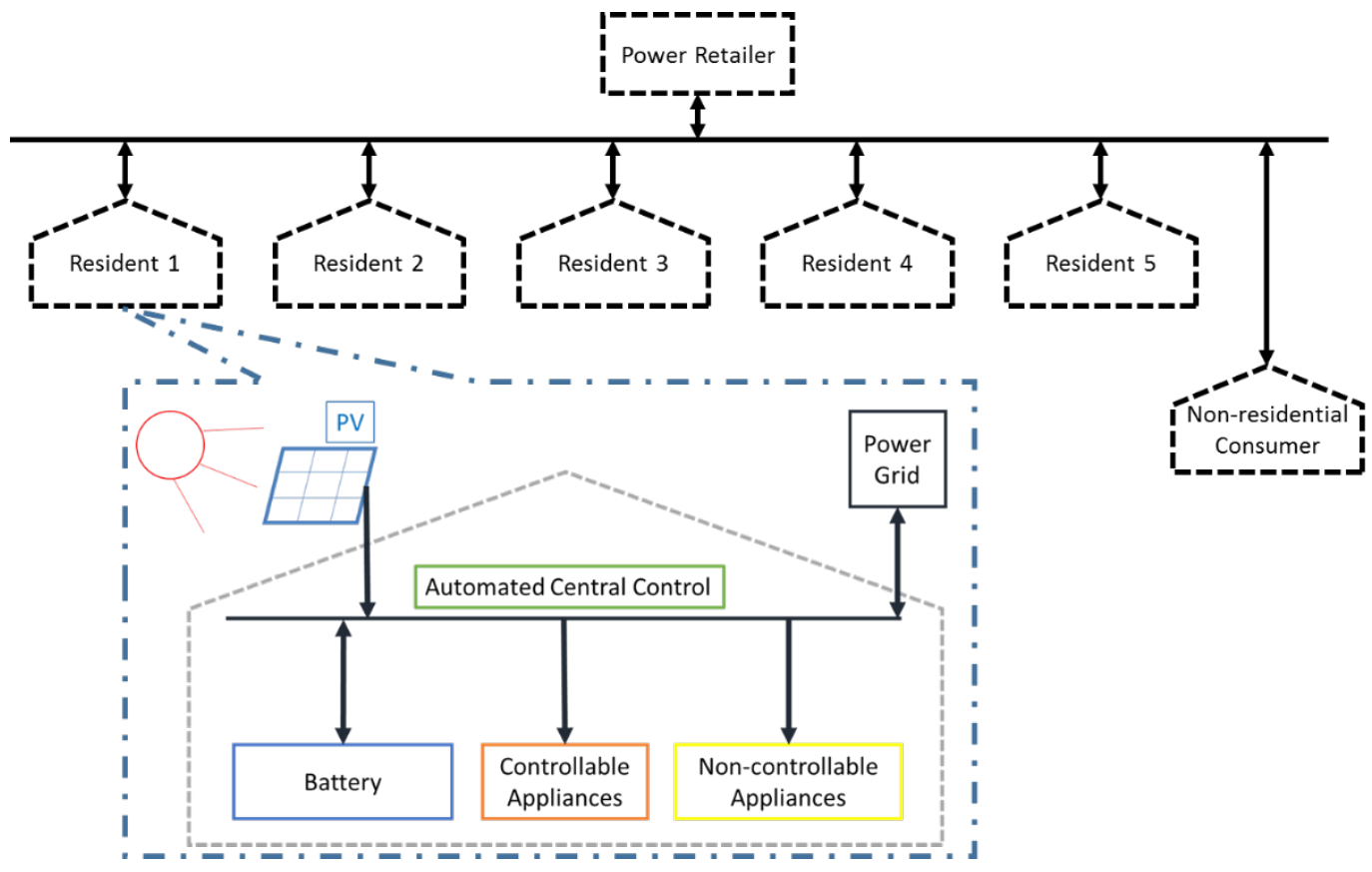

Figure 1 Structure of the target system

\section{Non-residential Load}

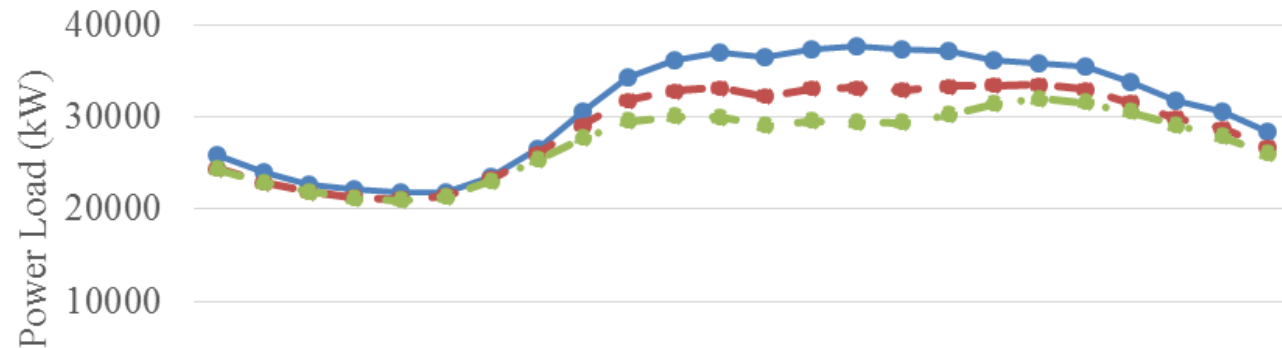

0

$\begin{array}{llllllll}1 & 4 & 7 & 10 & 13 & 16 & 19 & 22\end{array}$

Hour

$\rightarrow$ Summer $\quad-$ Winter Mid 
Figure 3 Non-controllable load of one household

532

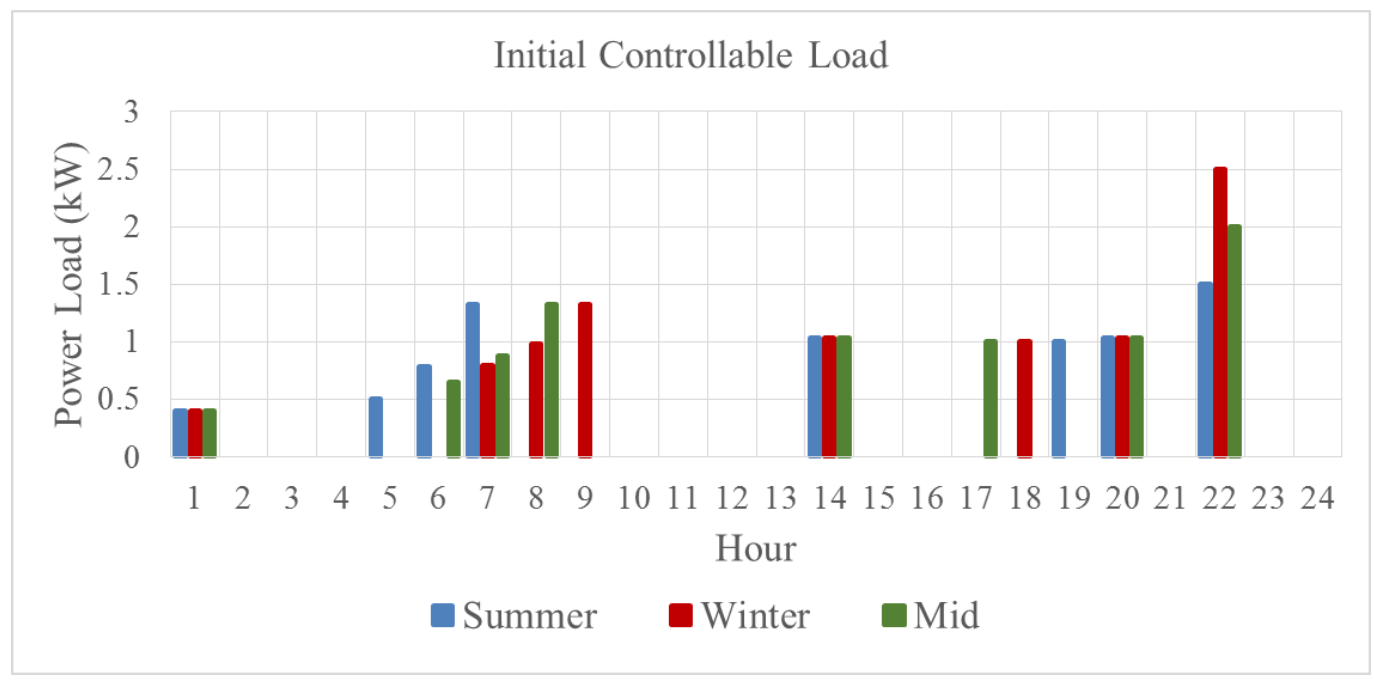



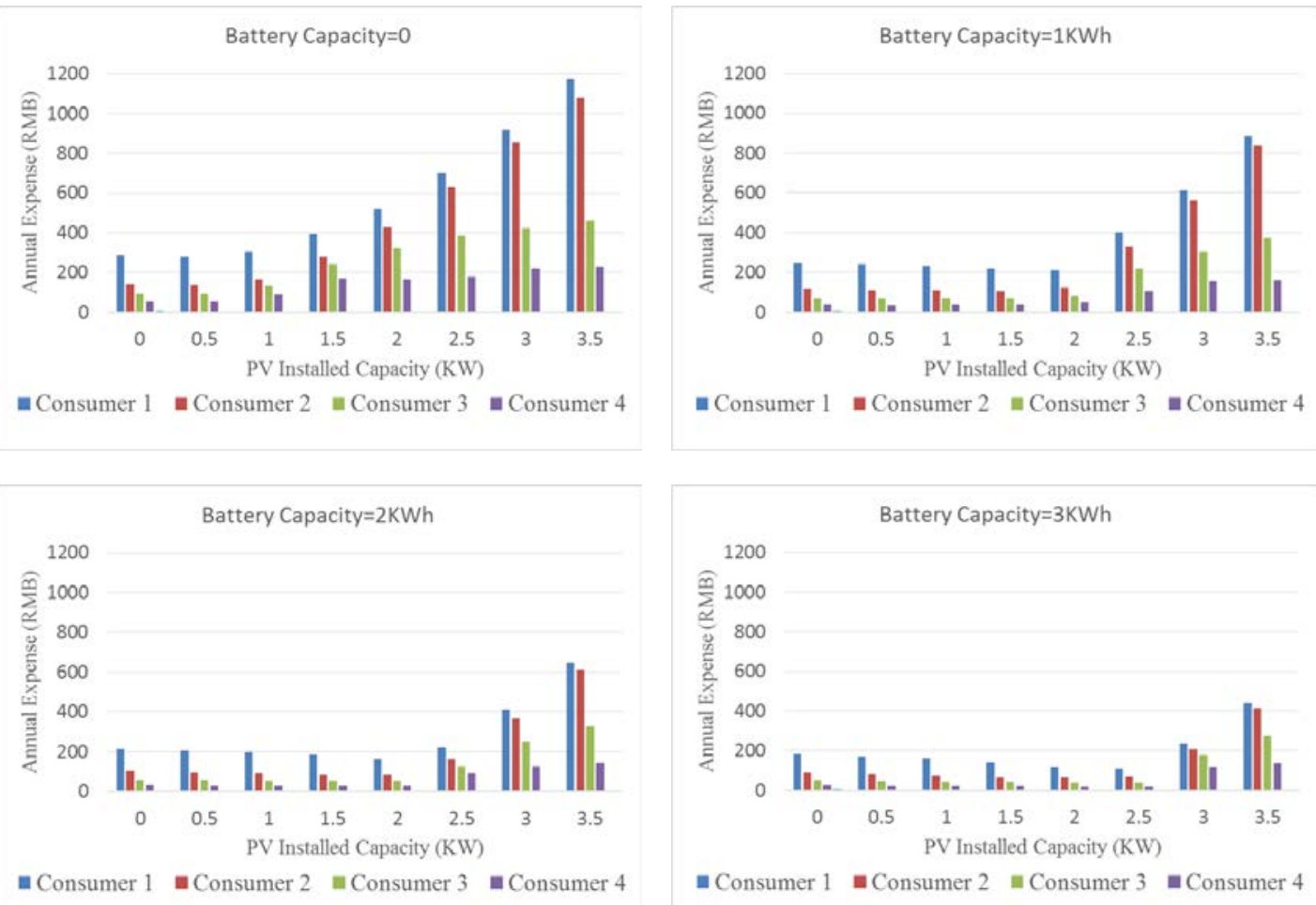

Figure 6 Saved annual electricity power expense of one household comparing to 

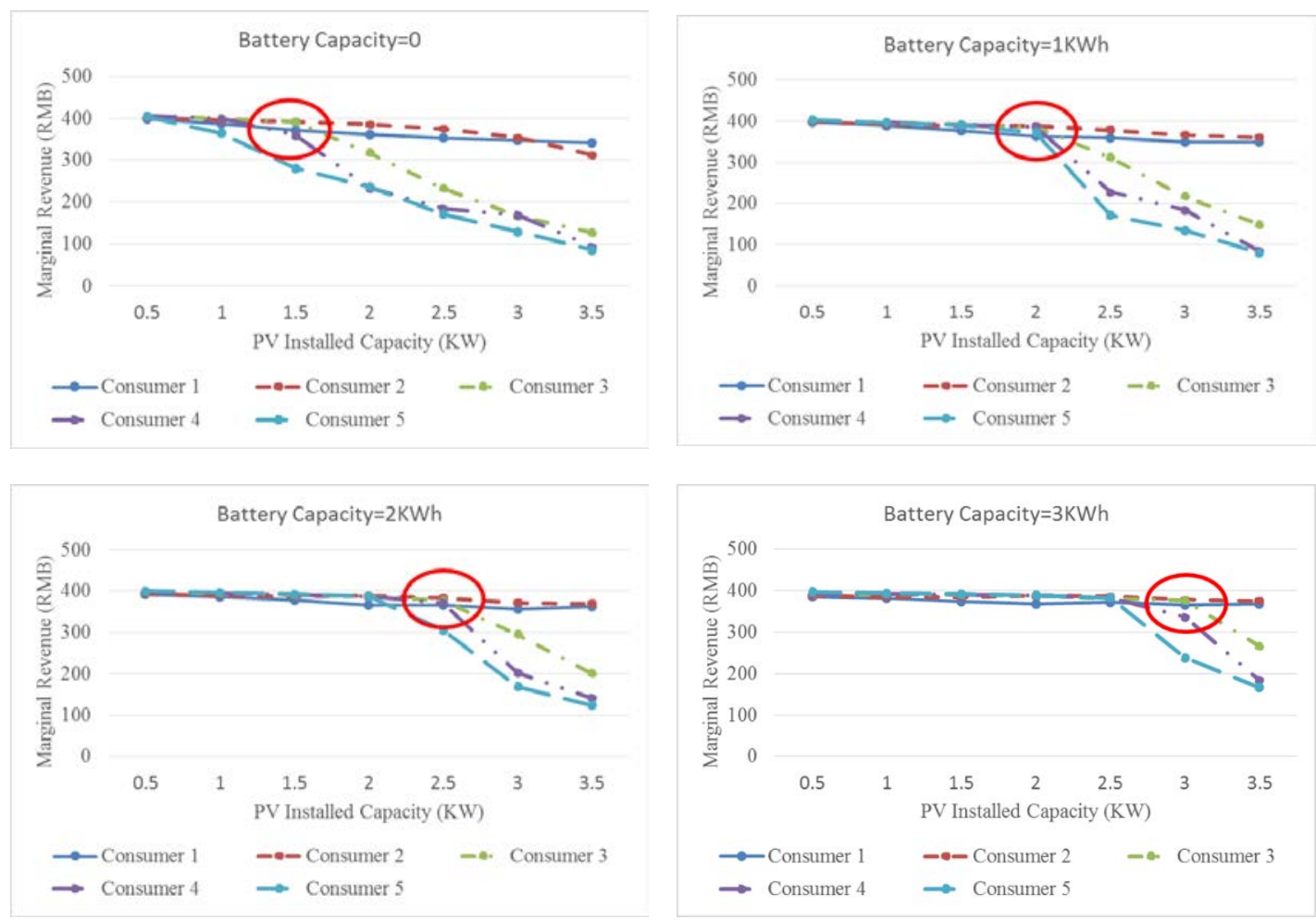

Figure 7 Marginal revenue of new installed PV capacity under different battery
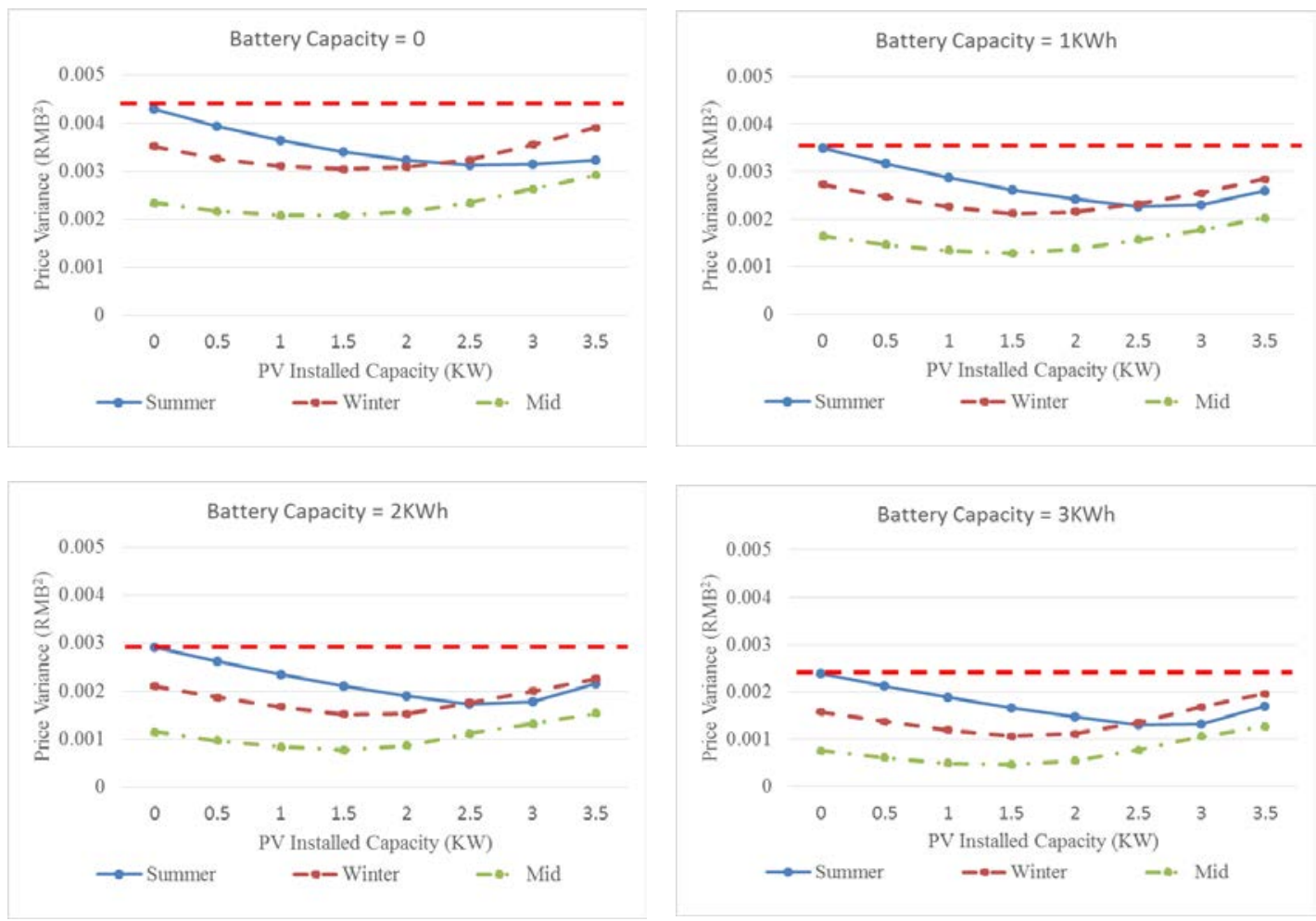


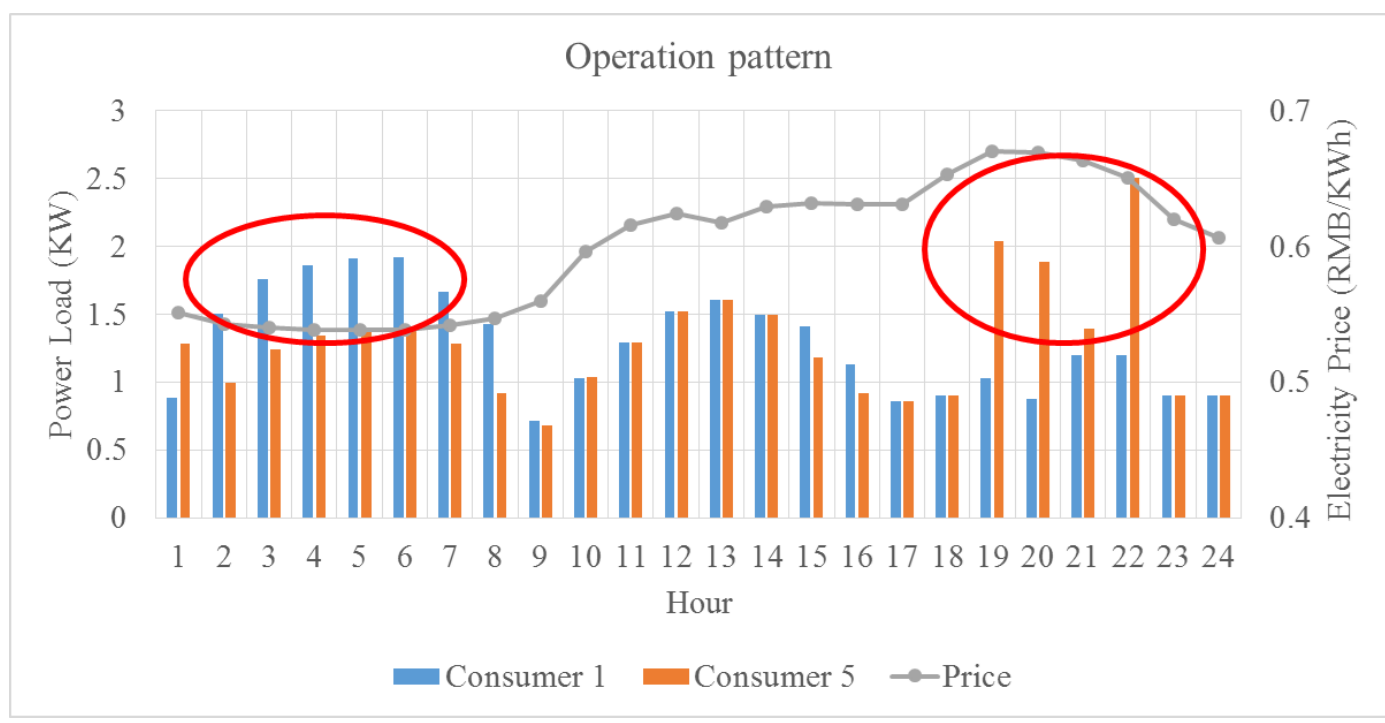

549 Figure 9 Operation patterns of consumer 1 and consumer 5 in the summer represent

553 The study was supported by the Science Foundation of China University of Petroleum ,

554 Beijing (No. 2462013YJRC015).

555 


\section{Reference}

557 [1] Hsu C-W. Using a system dynamics model to assess the effects of capital subsidies

558

559

560

561

562

563

564

565

566

567

568

569

570

571

572

573

574

575

576

577

578

579

580

581

582

583

584

585

586

587

588

589

590

591

592

593

594

595

and feed-in tariffs on solar PV installations. Applied Energy. 2012;100:205-17.

[2] Martin N, Rice J. The solar photovoltaic feed-in tariff scheme in New South Wales, Australia. Energy Policy. 2013;61:697-706.

[3] Zheng M, Meinrenken CJ, Lackner KS. Agent-based model for electricity consumption and storage to evaluate economic viability of tariff arbitrage for residential sector demand response. Applied Energy. 2014;126:297-306.

[4] Yan R, Saha TK, Modi N, Masood N-A, Mosadeghy M. The combined effects of high penetration of wind and PV on power system frequency response. Applied Energy. 2015;145:320-30.

[5] Wang G, et al., Multi-region optimal deployment of renewable energy considering different interregional transmission scenarios, Energy (2015), http://dx.doi.org/10.1016/j.energy.2015.08.060

[6] Zhang Q, McLellan BC, Tezuka T, Ishihara KN. An integrated model for long-term power generation planning toward future smart electricity systems. Applied Energy. 2013;112:1424-37.

[7] Matrawy KK, Mahrous AF, Youssef MS. Energy management and parametric optimization of an integrated PV solar house. Energy Conversion and Management. 2015;96:377-83.

[8] Bhatt J, Shah V, Jani O. An instrumentation engineer's review on smart grid: Critical applications and parameters. Renewable and Sustainable Energy Reviews. 2014;40:1217-39.

[9] Valenzuela J, Thimmapuram PR, Kim J. Modeling and simulation of consumer response to dynamic pricing with enabled technologies. Applied Energy. 2012;96:12232.

[10] Siano P. Demand response and smart grids—A survey. Renewable and Sustainable Energy Reviews. 2014;30:461-78.

[11] Muratori M, Schuelke-Leech B-A, Rizzoni G. Role of residential demand response in modern electricity markets. Renewable and Sustainable Energy Reviews. 2014;33:546-53.

[12] Kopsakangas Savolainen M, Svento R. Real-Time Pricing in the Nordic Power markets. Energy Economics. 2012;34:1131-42.

[13] Mazidi M, Zakariazadeh A, Jadid S, Siano P. Integrated scheduling of renewable generation and demand response programs in a microgrid. Energy Conversion and Management. 2014;86:1118-27.

[14] Kriett PO, Salani M. Optimal control of a residential microgrid. Energy. 2012;42:321-30.

[15] Tanaka K, Yoza A, Ogimi K, Yona A, Senjyu T, Funabashi T, et al. Optimal operation of DC smart house system by controllable loads based on smart grid topology. 
Renewable Energy. 2012;39:132-9.

[16] Yoza A, Yona A, Senjyu T, Funabashi T. Optimal capacity and expansion planning methodology of PV and battery in smart house. Renewable Energy. 2014;69:25-33. [17] Kahrobaee S, Asgarpoor S, Wei Q. Optimum Sizing of Distributed Generation and Storage Capacity in Smart Households. Smart Grid, IEEE Transactions on. 2013;4:1791-801.

[18] Agarwal T, Cui S. Noncooperative games for autonomous consumer load balancing over smart grid: Springer; 2012.

[19] Hung Khanh N, Song JB, Zhu H. Demand side management to reduce Peak-toAverage Ratio using game theory in smart grid. Computer Communications Workshops (INFOCOM WKSHPS), 2012 IEEE Conference on2012. p. 91-6.

[20] Su W, Huang AQ. A game theoretic framework for a next-generation retail electricity market with high penetration of distributed residential electricity suppliers. Applied Energy. 2014;119:341-50.

[21] Maharjan S, Quanyan Z, Yan Z, Gjessing S, Basar T. Dependable Demand Response Management in the Smart Grid: A Stackelberg Game Approach. Smart Grid, IEEE Transactions on. 2013;4:120-32.

[22] Wang Q, Zhang C, Ding Y, Xydis G, Wang J, Østergaard J. Review of real-time electricity markets for integrating Distributed Energy Resources and Demand Response. Applied Energy. 2015;138:695-706.

[23] Chan M, Esteve D, Escriba C, Campo E. A review of smart homes- present state and future challenges. Computer methods and programs in biomedicine. 2008;91:5581.

[24] Gabriel S, Conejo A, Fuller JD, Hobbs B, Ruiz C. Optimality and Complementarity. Complementarity Modeling in Energy Markets: Springer New York; 2013. p. 31-69. [25] Rosenthal RE. GAMS--a user's guide. 2004.

[26] Hobbs BF. Linear complementarity models of Nash-Cournot competition in bilateral and POOLCO power markets. Power Systems, IEEE Transactions on. 2001;16:194-202.

[27] Tung C-P, Tseng T-C, Huang A-L, Liu T-M, Hu M-C. Impact of climate change on Taiwanese power market determined using linear complementarity model. Applied Energy. 2013;102:432-9.

[28] MC F, TS M. GAMS/PATH user guide2000.

[29] National Bureau of Statistics of China NDaRC. CESY (China Energy Statistical Yearbook). 2013.

[30] Rastegar M, Fotuhi-Firuzabad M, Aminifar F. Load commitment in a smart home. Applied Energy. 2012;96:45-54.

[31] White LV, Lloyd B, Wakes SJ. Are Feed-in Tariffs suitable for promoting solar PV in New Zealand cities? Energy Policy. 2013;60:167-78.

[32] Campoccia A, Dusonchet L, Telaretti E, Zizzo G. Comparative analysis of different supporting measures for the production of electrical energy by solar PV and Wind systems: Four representative European cases. Sol Energy. 2009;83:287-97. 
638 [33] de La Tour A, Glachant M, Ménière Y. Predicting the costs of photovoltaic solar 639 modules in 2020 using experience curve models. Energy. 2013;62:341-8.

640 [34] Candelise C, Winskel M, Gross RJK. The dynamics of solar PV costs and prices 641 as a challenge for technology forecasting. Renewable and Sustainable Energy Reviews. 642 2013;26:96-107.

643 